\title{
HUMANIZAÇÃO: uma leitura a partir da compreensão dos profissionais da enfermagem
}

\author{
M aria de L ourdes Custódio DUARTE ${ }^{a}$, A delita N ORO ${ }^{b}$
}

\section{RESUM 0}

0 estudo busca compreender de que forma os profissionais de enfermagem realizam as suas práticas profissionais pautadas pela humanização. É uma investigação qualitativa, realizada em uma unidade de internação oncológica pediátrica de um hospital geral no R io G rande do Sul. Os sujeitos do estudo foram enfer meiros e técnicos de enfermagem, totalizando 11 profissionais. A partir da análise dos dados emergiram três categorias: compreensão de humanização, concretização da humanização na prática e o levantamento de sugestões para um trabalho humanizado. Concluímos que cada profissional deter mina a forma de realizar suas práticas para tornar o cuidado humanizado, no entanto, isto implica em escuta ativa e relações interpessoais consolidadas através de debates e reuniões periódicas.

D escritores: Humanização da assistência. Comunicação. Assistência hospitalar. Enfer magem pediátrica.

\section{RESUMEN}

E I estudio trata de comprender cómo el personal de enfermería lleva a cabo SU S prácticas profesionales pautadas por la humanización. E s una investigación cualitativa realizada en una unidad de oncología pediátrica hospitalaria del H ospital $G$ eneral en Río G rande do Sul, B rasil. L os sujetos del estudio fueron enfermeras y técnicos de enfermería, un total de once profesionales. E I análisis se llevó a cabo a través de tres categorías: la comprensión de la humanización, la concretización de la humanización en la práctica y el levantamiento de sugerencias para un trabajo humaniz ado. Seconcluyequecada profesional determina cómo llevar a cabo sus prácticas para hacer el cuidado humanizado, sin embargo esto requiere de una atención activa y de las relaciones inter per sonales consolidadas a través de la discusión y reuniones periódicas.

Descriptores: H umanización de la atención. Comunicación. A tención hospitalaria. E nfermería pediátrica.

Título: H umanización: una lectura de la comprensión de los profesionales de enfermería.

\section{ABST RACT}

T he study seeks to understand how the nursing staff carry out their professional practices guided by humanization. It is a qualitative research carried out in a pediatric oncology inpatient unit of a general hospital in R io G rande do Sul, B razil. Eleven nurses and nursing technicians partcicipated as subjects of the study. Three categories emerged in the analysis: comprehension of humanization, realization of humanization and suggestions for a humanepractice T he conclusion indicates that each professional determines how they will carry out their practices to humanize care Yet, this requires active listening and interpersonal relationships consolidated through discussion and regular meetings.

D escriptors: H umanization of assistance. Communication. $\mathrm{H}$ ospital care P ediatric nursing.

$T$ itle: $\mathrm{H}$ umanization: a reading from the understanding of nursing professionals.

\footnotetext{
a M estre em Enfer magem Psiquiátrica e Ciências H umanas, D outoranda em Enfermagem pelo Programa de Pós-G raduação da E scola de Enfermagem da Universidade Federal do Rio Grande do Sul (PPGENF-UFRGS), Professora Assistente da U niversidade Federal do Pampa (U nipampa), Porto A legre, Rio G rande do Sul, Brasil.

b Especialista em Oncologia, Enfermeira Assistencial do Hospital M ãe de D eus de Porto Alegre, Rio Grande do Sul, Brasil.
} 


\section{INT RODUÇÃO}

0 processo de Humanização nas instituições de saúde surge na atualidade para que se possa repensar as práticas cotidianas de trabalho, reformulando 0 atendimento que se vem prestando aos usuários desses serviços. N esse cenário, não é suficiente o hospital adquirir modernos equipamentos, dispor de estrutura moder na apropriada aos cuidados de saúde, se não estiver voltado para a satisfação das necessidades dos usuários e os trabal hadores que os atendem ${ }^{(1)}$.

$\mathrm{Na}$ atualidade, a preocupação é tamanha sobre a Humanização, que M inistério da Saúde implantou, no ano 2000, o Programa Nacional de Humanização da Assistência Hospitalar e, posteriormente, a Política Nacional de Humanização $(\mathrm{PNH})$, visando atender às demandas subjetivas manifestadas pelos usuários e trabalhadores dos serviços de saúde ${ }^{(2)}$. O PNH é um pacto, uma construção coletiva, que só pode acontecer a partir da construção e troca de saberes, através do trabalho em rede, com equipes multiprofissionais, da identificação das necessidades, desejos e interesses dos envolvidos, do reconhecimento de gestores, trabaIhadores e usuários como sujeitos ativos e protagonistas das ações de saúde, e da criação de redes solidárias e interativas, participativas e protagonistas do Sistema Ú nico de Saúde (SU S) ${ }^{(3)}$.

No contexto da enfermagem, 0 aspecto humano do cuidado com certeza, é um dos mais difíceis de ser implementado. A rotina diária e complexa que envolve os mais variados ambientes que a enfermagem atua faz com que os membros da sua equipe, na maioria das vezes, esqueçam de tocar, conversar e ouvir o ser humano que está à sua frente ${ }^{(4)}$. Certamente, um profissional deve ser munido de condições para exercer uma boa técnica, porém ela não é tudo. Quando esses profissionais se deparam com situações que envolvem caridade, solidariedade, frater nidade, ao efetivá-las na prática, estes serão lembrados ao longo da vida dos pacientes.

A humanização deve fazer parte da filosofia de enfermagem. 0 ambiente físico, os recursos materiais e tecnológicos são importantes, porém não mais significativos do que a essência humana. E sta, sim, irá conduzir o pensamento e as ações da equipe de enfermagem, tornando-o capaz de criticar e construir uma realidade mais humana, menos agressiva e hostil para as pessoas que diaria- mente vivenciam as instituições de saúde ${ }^{(5)}$. A humanização do atendimento em saúde subsidia 0 atendimento, a partir do amparo dos princípios predeter minados como: a integralidade da assistência, a eqüidade e 0 envolvimento do usuário, além de favorecer a criação de espaços que valorizem a dignidade do profissional e do paciente $e^{(6)}$.

0 interesse em desenvolver o tema surgiu no decorrer do trabalho em enfermagem, realizado em diversas U nidades de Inter nação Oncológica Pediátrica, no qual se observou a dificuldade da equipe de enfermagem em desempenhar um cuidado que atendesse as necessidades humanas dos pacientes internados, instigando na busca por compreender o processo de humanização na práxis da enfermagem.

Nesse cenário, é importante abordar a necessidade de humanização do cuidado de enfermagem em uma unidade de inter nação oncológica pediátrica, para provocar uma reflexão da equipe de enfermagem em relação aos cuidados prestados às crianças inter nadas. N este estudo, entende-se que humanizar é uma medida que visa, sobretudo, tornar efetiva a assistência ao indivíduo criticamente doente, considerando-o como um ser biopsicossocioespiritual. Além de envolver o cuidado ao paciente, a humanização estende-se a todos aqueles que estão envolvidos no processo saúdedoença.

O tema humanização parece ser algo simples e fácil de ser levado a ter mo quase que natural, já que seres humanos cuidam de seres humanos. Então, por que o processo de H umanização não se efetiva na prática cotidiana dos profissionais nas instituições de saúde?

A partir deste questionamento o presente estudo tem por objetivo geral compreender de que forma os profissionais de enfermagem realizam as suas práticas pautadas na humanização em uma U nidade de Internação Oncológica Pediátrica. T emse por objetivos específicos identificar as estratégias utilizadas pela equipe de enfermagem para 0 exercício de um cuidado humanizado e desvelar as dificuldades enfrentadas no cotidiano dessas equipes.

A contribuição deste trabalho é fundamentar o processo de humanização e perceber a nova realidade exercida pela enfermagem, além de proporcionar subsídios para a construção do conhecimento sobre o tema, estimulando a formulação de 
um planejamento estratégico para educação continuada nas instituições de saúde.

\section{METODOLOGIA}

Este estudo tem caráter exploratório-descritivo, com abordagem qualitativa(7), sendo realizado em uma unidade de internação pediátrica oncológica de um hospital geral no Rio Grande do Sul. Essa unidade presta assistência exclusivamente ao SU S à crianças portadoras de neoplasias.

Os sujeitos do estudo compreenderam a totalidade de enfer meiros da unidade, três, e oito técnicos de enfermagem que atuam nos turnos manhã e tarde que concordaram em participar do estudo, totalizando onze entrevistados. U tilizou-se a repetição de dados nas entrevistas como critério para delimitar o tamanho da amostra. 0 tipo da amostra foi intencional, por convite, tendo como critério de inclusão o tempo mínimo de um ano de vínculo com a instituição.

A coleta dos dados ocorreu no período de julho a agosto de 2007, por meio de entrevistas individuais semi-estruturadas, consistindo de quatro questionamentos: 0 que é para você humanização? Como a humanização se concretiza na prática de um profissional da saúde? 0 que dificulta ter uma prática humanizada? 0 que você sugere para o trabal ho, no sentido da humanização?

Procedeu-se à leitura integral das entrevistas, adotando-se o referencial de análise temática para apreciação crítica do conteúdo, buscando-se encontrar os trechos significativos para a constituição dos temas abordados nas obras pesquisadas, em relação ao objetivo do estudo(7). Seguindose os passos de préanálise e exploração do material foi possível a organização e leitura repetida do corpus de pesquisa. Posteriormente, procedeu-se ao tratamento e interpretação dos resultados obtidos, descritos em unidades de registro e de contexto, que permitiram o agrupamento de idéias relevantes em categorias, representadas por três eixos temáticos de discussão, a saber: compreensão de humanização, concretização da humanização na prática e sugestões para um trabal ho humanizado. Os sujeitos que compuseram a amostra do estudo foram numerados de um a onze e foram denominados com o nome de flores.

A pesquisa foi aprovada pelo comitê de ética do referido hospital, conforme protocolo 071/07, sendo considerados os aspectos éticos, envolvendo seres humanos, em conformidade com o previsto na Resolução 196/ 96 do Conselho N acional de Saúde ${ }^{(8)}$. Os participantes assinaram o Termo de Consentimento Livre e Esclarecido após terem sido informados sobre os objetivos da pesquisa.

\section{APRESENTAÇÃO E ANÁLISE DOS RESULTADOS}

\section{Compreensão de humanização}

A prática atual da enfermagem deve ser pautada na noção de cuidado humanizado, como uma ação complexa e integral, respeitando, acolhendo as necessidades de cada sujeito. Assim, o cuidado pressupõe capacidade para a escuta e o diálogo, além de disponibilidade para perceber 0 outro, como um sujeito com potencialidades, resgatando a autonomia e estimulando a cidadania.

0 conjunto das falas possibilitou verificar que a compreensão de humanização é ampla. A noção de integralidade da atenção ocorre pelo reconhecimento de que cada pessoa é um todo indivisível e social, que as ações de promoção e recuperação da saúde não podem ser fragmentadas ${ }^{(9)}$.

E u acredito queéver 0 ser humano como um todo, desde as condições sociais, econômicas e psicológicas (2 Jasmin).

E $m$ priméro lugar, tratar 0 indivíduo com ética, através de uma visão holística, o indivíduo no completo (4 $M$ argarida).

T ratar as pessoas bem, não chamar o paciente pelo número do leito ou pela patologia (6 H ortência).

No processo de humanização, não há regras, nem fórmulas que o tornem viável, porque ele depende fundamentalmente do profissional de saúde e das suas concepções em relação ao processo de humanização(10). Como alter nativas de otimização, sugerem mais investimentos na formação de recursos humanos e na compreensão do paciente como ser único e indivisível. Estes aspectos vêm ao encontro do que é apontado pelos sujeitos de pesquisa como sugestões para o atendimento humanizado.

$\mathrm{Na}$ perspectiva de intervenção ampliada de assistência, as ações da enfermagem devem cons- 
tituir-se em um cuidado que vise a totalidade do indivíduo, ou seja, uma pessoa com sentimentos e com família, inserida em um contexto social que não pode ser descartado e, sim, utilizado em prol do seu cuidado. 0 atendimento integral vai além da formulação de um planejamento terapêutico, contempla a reorientação das relações entre 0 Estado e a Sociedade e o olhar para o sujeito-usuário dentro de uma lógica de atendimento que considere o cuidado nas mais diversas dimensões do ser humano(11).

Enfim, a humanização estabelece-se como construção de atitudes ético-estético-políticas, em sintonia com um projeto de co-responsabilidade e qualificação dos vínculos entre os profissionais e, entre estes, e os usuários na produção de saúde ${ }^{(12)}$. N este cenário, o processo de humanização consiste na possibilidade de vislumbrar o paciente como um ser complexo, repleto de subjetividades, traduzindo um saber-fazer pautado pela ética.

A compreensão de humanização dos sujeitos pesquisados implica em relações entre profissionais. Assim, nas instituições de saúde, as atividades da equipe de enfermagem devem estar pautadas no acolhimento e integralidade do usuário, possibilitando um cuidado humanizado.

$N$ este sentido a humanização supõe troca de saberes, incluindo os usuários e sua rede social, priorizando o diálogo entre os profissionais e 0 trabalho em equipe.

U nião verdadeira entre os profissionais, disponibilidade, menos jogos de disputa. As pessoas perdem muito tempo com picuinhas, sendo que tem muito trabaIho a fazer (4 $\mathrm{M}$ argarida).

Parece que a gente não toma as decisões juntas, parece que a gente está só e não pode tentar melhorar nada (5 Lírio da Paz).

Os entrevistados trazem a noção da importância de um trabalho multidisciplinar para um cuidado humanizado, complexo. Porém fica evidente a dificuldade desse trabalho em equipe no cotidiano do local do estudo.

No trabal ho multidisciplinar há uma associação de disciplinas com um objetivo comum, sem que cada uma tenha que modificar significativamente sua maneira de compreender as coisas. A comunicação é fundamental no trabalho em equipe para a interação dos profissionais, na integração dos saberes e para a troca de informa- ções, visando a construção de um projeto comum, 0 atendimento humanizado. N esse contexto, a integração de diferentes saberes só vem enriquecer o trabal ho e proporcionar um cuidado mais completo e repleto de possibilidades para o sujeito que buscou o serviço de saúde.

A humanização é um processo amplo, demorado e complexo, ao qual se oferecem resistências, pois envolve mudanças de comportamento, que sempre despertam insegurança. Os padrões conhecidos parecem mais seguros; al ém disso, os novos não estão prontos nem em decretos nem em livros, não tendo características generalizáveis, pois cada profissional, cada equipe, cada instituição, terá seu processo singular de humanização ${ }^{(13)}$. N esse sentido, a humanização tem sido associada a distintas e complexas categorias relacionadas à produção e gestão de cuidados e saúde, tais como: integralidade, satisfação do usuário, necessidades de saúde, qualidade na assistência, gestão participativa, protagonista dos sujeitos e a intersubjetividade envolvida no processo de atenção(2).

\section{Concretização da humanização na prática}

N esta categoria, analisa-se como acontece a humanização na prática profissional, como esta se torna real, a partir da percepção individual de cada sujeito da pesquisa.

A leitura das entrevistas permite constatar que muitas podem ser as práticas humanizadas empregadas pelos profissionais, mas o que chama a atenção é a disponibilidade dos entrevistados para realizá-las, apesar das dificuldades encontradas. Entendem que a humanização do cuidado pode acontecer mesmo sem condições adequadas e que cada indivíduo viabiliza meios para al cançá-la.

$\mathrm{N}$ a Oncologia a gente não tem nenhum brinquedo pedagógico, não existe nada lúdico, para levar até 0 paciente, mesmo assim a gentetenta brincar, para ame nizar um pouco etrabal har de uma forma mais humana (2 Jasmin).

As verbalizações permitem constatar que os profissionais são comprometidos com seus afazeres diários e, mesmo com dificuldades impostas pela área física ou impossibilidades financeiras, criam condições que podem amenizar o sofrimento do paciente. N esse contexto, o brinquedo pode ser entendido como um dispositivo para amenizar o so- 
frimento causado pela doença e pela abrupta separação do convívio social (Família, Amigos, Escola, O bjetos Pessoais, A nimais de E stimação) por meio da representação de sentimentos como: medo, angústia, saudade, tensão e outros ${ }^{(14)}$.

O brincar é muito importante para a criança, pois por meio dela a aprendizagem se torna mais significativa. Pelo brincar a criança manifesta as suas decisões, os seus medos, os seus gostos, dúvidas, sua curiosidade, seu desejo de criar, enfim, quando brinca, a criança se defronta com desafios e problemas, devendo constantemente buscar soluções para as situações a elas colocadas ${ }^{(15)}$.

0 ato de brincar favorece a externalização e elaboração de conteúdos do mundo mental da criança, proporcionando um espaço lúdico para as crianças hospitalizadas e momentos de descontração, estimulando a expressão e comunicação da imagem da realidade em que estão inseridas. Assim, a atitude do entrevistado em "brincar" com as crianças pode ser entendida com uma tentativa de humanizar 0 ambiente hospitalar para que a internação não seja um momento tão doloroso e difícil para as crianças inter nadas.

Em um ambiente de poucos recursos financeiros, porém de muita criatividade da equipe de enfermagem, foi criado o "sapinho" W ilson. 0 "sapinho" W ilson é uma fantasia lúdica que teve custo baixo e que deixa as crianças encantadas e motivadas. Esse dispositivo ameniza o tratamento doloroso e torna-o mais ameno e tranqüilo.

Começou comigo e uma colega. É um fantochee écomo se ele fosse um paciente também. As crianças se vêem nele (6 H ortência).

E u o colocava no soro, como se fosse um paciente $E$ u levo ele para ver as crianças. J á criou uma simbologia aqui na $\mathrm{O}$ ncologia. $\mathrm{N}$ o próximo mês a gente locou um galpão para arrecadar brinquedos que aqui não tem (4 M argarida).

0 brinquedo aparece à criança como um jogo, uma fantasia muito próxima ao real, uma manifestação do sentir do saber, o que permite a ela inventar, renovar e discordar. Através do brinquedo ou mesmo de um livro, a criança consegue não apenas se relacionar e compreender o mundo, mas consegue também superar problemas presentes em seu cotidiano ${ }^{(14)}$.

A criança internada não está preocupada se o brinquedo que lhe é oferecido é confeccionado de forma simples, o que Ihe interessa é a forma na qual é cuidada. N esse sentido, não basta dispor de espaço físico adequado, suporte e infra-estrutura se as práticas profissionais não forem sensíveis ao meio. Os profissionais de saúde, nesse contex to de poucos recursos, devem ser criativos, sentir a necessidade de doação, ouvindo e percebendo 0 outro como seu semel hante. A criatividade é também pontuada na entrevista no momento em que a equipe organiza um evento para arrecadar brinquedos às crianças, envolvendo familiares e a comunidade como um todo.

A humanização da assistência possibilita levantar questões fundamentais que podem auxiliar na construção das políticas em saúde. H umanizar é, então, ofertar atendimento de qualidade, articulando os avanços tecnológicos com o acolhimento, com melhorias dos ambientes de cuidado e das condições de trabal ho dos profissionais(2). As dificuldades estruturais, que muitas vezes fogem do poder pessoal, ganham forças nas melhorias que os próprios profissionais tentam fazer, como arrecadações de brinquedos e festas, uma forma de proporcionar um ambiente mais acolhedor e humano.

A sociedade contemporânea tem cada vez mais dificuldade em pensar a questão da morte e do morrer. Vários profissionais de saúde (cuidadores formais) estão envolvidos com os cuidados ao indivíduo no final da vida e em diferentes locais (hospitais, ambulatórios, asilos e residências). Quando a cura não é mais possível, quando a ciência se acha incapaz de resolver o problema trazido pela doença, a equipe de saúde continua prestando um cuidado humanizado diante do doente, na sua dignidade, na sua fragilidade e na sua necessidade de ser amparado, cuidado e amado(16).

As atividades assistenciais humanizadas prestadas a uma criança com câncer suscitam dos profissionais momentos de satisfação e realização profissional, não se preocupando com o dia de amanhã.

A gente produz o cuidado, 0 bem estar da criança, tentando focar para ela viver um dia de cada vez, não se preocupar que hoje ela ta brincando e amanhã ela vai morrer, a gente procura fazer tudo que esta ao nosso alcance (7 G irassol).

Das doenças crônicas degenerativas, o câncer é uma das que mais trazem sofrimento de diversas dimensões acometem tanto os portadores 
da doença como seus familiares e cuidadores. Entender o impacto do câncer nos indivíduos é essencial para estabelecer estratégias de cuidados $^{(16)}$. N esse sentido, uma das estratégias encontrada pelo entrevistado foi prestar o cuidado humanizado não se importando com o desfecho do tratamento, proporcionando tudo o que estiver ao seu alcance enquanto profissional de saúde. A pesar da impossibilidade de cura, isso não significa a deteriorização da relação equipe de enfer magem-paciente, mas, sim, o estreitamento dessa atenção, a qual, certamente, trará benefícios para ambos.

A análise desta categoria permitiu identificar que muitas são as práticas estabelecidas para concretizar o processo de humanização na prática da equipe de enfer magem. $\mathrm{N}$ o setor onde foram coletados os dados, cada profissional se empenha para fazer do seu local de trabalho o melhor, possibilitando que os pacientes possam ser beneficiados com o empenho coletivo de toda a equipe.

\section{Sugestões para um trabalho humanizado}

N esta categoria, são expostas as sugestões trazidas nas falas dos entrevistados como forma de tornar o trabalho mais humanizado. A leitura dos relatos possibilitou identificar alguns aspectos em comum, a saber: comprometimento pessoal com as questões de um cuidado de qualidade, participação nas reuniões de equipe, acolhimento e participação da família no cuidado.

T u acol hes a família toda, não é só o paciente. $N$ esse acol himento tu orienta, dando segurança (11 Begônia).

$\mathrm{N}$ as reuniões, 0 grupo de trabal ho, pode falar a mesma língua e agir com coerência maior em relação aos pacientes (2 Jasmin).

$\mathrm{N}$ ão pensar na quantidade, mas na qualidade do atendimento. A gente tem que se conscientizar e se colocar no lugar do outro (7 Girassol).

É possível afirmar que muitas são as idéias que os profissionais têm para que a humanização seja efetivada nas práticas diárias. A equipe de saúde deve estabelecer objetivos que englobam a humanização, real izando discussões sobre como meIhorar 0 atendimento prestado aos usuários do SUS. As discussões sobre o tratamento dos pa- cientes e a forma na qual deve ser prestado o cuidado, podem ser debatidas em reuniões.

Durante as reuniões de equipe, o projeto terapêutico individual do paciente é discutido tendo em vista que é lugar onde as relações se constroem e se fortificam, ao se responsabilizar em conjunto, com respeito, intimidade e cumplicidade, pela co-gestão do cotidiano. $N$ as reuniões diárias a equipe se conhece e aprende a fazer junto, trabaIhando as questões que surgem da situação nova, não hierarquizada, própria desse trabal ho interdisciplinar ${ }^{(17)}$. As reuniões de equipe devem continuar a fim de estabelecer vínculo entre seus membros e organizar como o "cuidado" deve ser concretizado.

N esse cenário, é necessário implantar, estimular e fortalecer $\mathrm{G}$ rupos de T rabal ho de Humanização com plano de trabalho definido, reforçar o conceito de clínica ampliada, compromisso com 0 sujeito e seu coletivo, co-responsabilidade de gestores, trabalhadores e usuários no processo de produção de saúde, sensibilizar as equipes de saúde em relação ao problema da comunidade ${ }^{(18)}$. E ssas diretrizes encontram-se nas entrelinhas das falas analisadas, viabilizando mudanças positivas para os nossos locais de atuação.

A participação da família e da comunidade em geral também se faz presente e necessárias para que os sonhos fiquem cada vez mais próximos da realidade. A família é o primeiro núcleo social a se mobilizar numa situação de enfermidade e é um elemento fundamental no processo de reabilitação do doente, tornando-se, assim, um referencial para os serviços de saúde(19).

E videnciou-se a partir das sugestões dos entrevistados que há interesse e empenho no comprometido destes profissionais, trazendo à discussão novas idéias para que a humanização aconteça nas práticas diárias da equipe de enfermagem e para a equipe multidisciplinar como um todo. N ota-se também que os sujeitos desde estudo sentiram-se protagonistas do tratamento dos pacientes na unidade oncológica, servindo de agentes de mudanças positivas no contexto da humanização no cotidiano de trabalho.

\section{CONSIDERAÇÕES FINAIS}

Ao longo desse estudo, percebemos que valores como a ética, respeito e carinho são sentimentos que deixam o paciente tranqüilo e seguro 
frente ao tratamento e prognóstico. N esse sentido, a compreensão de humanização permeia o cotidiano dos entrevistados orientando os profissionais nas suas práticas.

0 fator das condições físicas da unidade e poucos recursos materiais não são fatores determinantes para concretizar ou não o processo de humanização no local. A pesar de todas as dificuldades enfrentadas pelos profissionais isso não impediu que eles organizassem formas alternativas para amenizar o sofrimento das crianças. E ssa questão é facilitada quando a comunidade e a família são envolvidas nesse processo.

Outra dificuldade verbalizada pelos entrevistados para a efetiva humanização das suas práticas foi a das relações humanas dentro do local de trabalho. Em um trabalho em equipe os objetivos frente a uma realidade devem ser similares para que todos possam atingir um objetivo maior, o de concretizar a humanização nas práticas dos profissionais de saúde, oferecendo a sociedade uma rede de saúde mais frater na e igual itária.

No local estudado há o espaço para discussões sobre o tema e muitos profissionais entendem que a tecnologia é uma importante ferramenta no processo saúde-doença, porém o cuidado prestado por seres humanos não deve ser substituído.

Portanto, deve-se transcender a fragmentação do cuidado desde a formação dos profissionais de saúde, pois ainda existem profissionais que carecem de conhecimentos e preparo para realizar um trabalho multidisciplinar e humano, superando a teoria dos programas ministeriais. A ssim, as instituições de saúde devem estimular o cuidado humanizado como fator indispensável no cotidiano de quem cuida, além de promover programas institucionais sobre o tema.

\section{REFERÊNCIAS}

1 Deslandes SF. Humanização dos cuidados em saúde: conceitos, dilemas e práticas. Rio de Janeiro: F iocruz; 2006.

2 Bergan C, Bursztyn I, Santos COM , T ura L F R. H umanização: representações sociais do hospital pediátrico. Rev G aúcha Enferm. 2009;30(4):656-61.

3 M inistério da Saúde (BR). Política $\mathrm{N}$ acional de H umanização: H umaniza SU S [ I nternet] . Brasília (DF); 2005 [ citado 2010 fev 21]. Disponível em: http:/ / portal.saude.gov.br/ saude/ area.cfm?id_area=389.
4 Vila VSC, Rossi LA. 0 significado cultural do cuidado humanizado em unidade de terapia intensiva: "muito falado e pouco vivido". Rev Latino-A m Enfermagem. 2002;10(2):137-44.

5 Casate JC, Corrêa AK. H umanização do atendimento em saúde: conhecimento veiculado na literatura brasileira de enfermagem. Rev Latino-Am E nfermagem. 2005;13(1):105-11.

6 A mestoy SC, Schwartz E, Thofehrn M B. A humanização do trabalho para os profissionais de enfermagem. Rev Esc Enferm USP. 2006;19(4):444-9.

7 M inayo M CS. 0 desafio do conhecimento: pesquisa qualitativa em saúde. 10ª ed. São Paulo: H ucitec; 2007.

8 M inistério da Saúde (BR), Conselho N acional de Saúde. Resolução 196, de 10 de outubro de 1996: diretrizes e normas regulamentadoras de pesquisas envolvendo seres humanos. Brasília (DF ); 1996.

$9 \mathrm{~N}$ asi C, Cardoso ASF, Schneider J, Olschowski A, W etzel $C$. Conceito de integralidade na atenção em saúde mental no contexto da reforma psiquiátrica. REM E: Rev M in Enferm. 2009;13(1):147-52.

10 Santana M L, Silva M J P. Como é sentida a experiência de estar na UTI sob a perspectiva de quem vivencia. SOBET I Rev. 2000;1(1):12-6.

11 Pinho LB, Kantorski LP, Saeki T, Duarte M LC, Souza J. A integralidade no cuidado em saúde: um resgate de parte da produção científica da área. Rev Eletrônica Enferm [I nternet] . 2007 [ citado 2010 maio 10];9(3):835-46. Disponível em: http:/ / www. fen.ufg.br/ revista/ v9/ n3/ v9n3a22.htm.

12 F reyre K. E ra uma vez: laboratório de sonhos. Recife: Editora da Universidade de Pernambuco; 2004.

13 M artins M CF. Humanização das relações assistenciais de saúde: a formação do profissional de saúde. São Paulo: Casa do Psicólogo; 2001.

14 Santos SM P. A ludicidade como ciência. Petrópolis: Vozes; 2001

15 Smole KS. Brincadeiras infantis nas aulas de matemática. Porto Alegre: Artmed; 2000. v. 1.

16 Silva RCF, Hortale VA. Cuidados paliativos oncológicos: el ementos para o debate de diretrizes nesta área. Cad Saúde Pública. 2006;22(10):2055-66. 
17 Rocha RM . 0 enfermeiro na equipe interdisciplinar do centro de atenção psicossocial e as possibilidades de cuidar. Texto Contexto E nferm. 2005;14(3): 350-7.

18 M inistério da Saúde (BR), Secretaria de Assistência à Saúde. Prog rama $\mathrm{N}$ acional de H umanização da Assistência Hospitalar [ Internet]. Brasília (DF);
2001 [ citado 2010 fev 20] . Disponível em: http:/ / bvsms.saude.gov.br/bvs/ publicacoes/ pnhah01. pdf.

19 Duarte M LC, Souza J, Kantorski LP, Pinho LB. Diferentes abordagens à família em saúde mental presentes na produção cientifica da área. Rev M in Enferm. 2007;11(1):66-72.
Endereço da autora / Dirección del autor / Author's address:

$M$ aria de Lourdes Custódio Duarte

Rua $\mathrm{G}$ onçalves Ledo, 20, ap. 203, Partenon

90610-250, Porto Alegre, RS

E-mail: malulcd@yahoo.com.br
Recebido em: 19/ 05/ 2010

A provado em: 10/ 12/ 2010 